\title{
HONGOS CAUSANTES DE ENFERMEDADES POSTCOSECHA EN CHAYOTE (Sechium edule (Jacq.) SW.) Y SU CONTROL IN VITRO
}

\author{
Siul D. Romero-Velazquez", Bertha Tlapal-Bolaños ${ }^{* *}$, Jorge Cadena-Iñiguez $^{* * *}$, Daniel Nieto-Ángel, \\ $M^{a}$. de Lourdes Arévalo-Galarza ${ }^{1 / *}$ \\ Palabras clave: Fusarium sp.; cucurbitáceas; fungicidas; Bacillus subtilis; procloraz. \\ Keywords: Fusarium sp.; cucurbita; fungicides; Bacillus subtilis; prochloraz.
}

Recibido: 17/11/14

\section{RESUMEN}

El fruto de chayote (Sechium edule (Jaqc.) Sw.) es una hortaliza de exportación de importancia para México y Costa Rica. El proceso comercial exige cumplir con estándares de calidad, que implican frutos sanos y libres de defectos. Sin embargo, debido a las condiciones de alta humedad que se desarrollan en los frutos empacados en películas plásticas, se han presentado rechazos en el mercado de exportación, por la presencia de enfermedades fungosas. El objetivo de este trabajo fue identificar morfológica (microscopía óptica y electrónica de barrido) y molecularmente (PCR: Polimerase Chain Reaction) las especies de hongos causales de las principales enfermedades postcosecha de chayote en frutos infectados procedentes de huertas comerciales para exportación, así como probar in vitro la efectividad de diversos productos comerciales en la inhibición del crecimiento de dichos hongos. Los resultados mostraron a Didymella bryoniae como el causante de "gomosis de las cucurbitáceas" y a Fusarium oxysporum y $F$. solani como causales de fusariosis o ahogamiento de guías; estos patógenos dañan la parte basal y media de frutos comerciales, además de Chaetomium globosum, un asociado al proceso infeccioso de Fusarium

1 Autor para correspondencia. Correo electrónico: larevalo@colpos.mx

* Recursos Genéticos y Productividad-Fisiología Vegetal. Colegio de Postgraduados. km 36.5 Carretera México-Texcoco, Montecillo, Texcoco, Estado de México, CP 56230 México.
Aceptado: 18/03/15

\begin{abstract}
Fungi that cause postharvest diseases in chayote (Sechium edule (Jacq.) Sw.) and their in vitro control. The fruit of chayote (Sechium edule (Jaqc.) Sw.) it is a vegetable of export of importance to Mexico and Costa Rica. The commercial process requires to accomplish high quality standards, which implies fruit healthy and free from defects. However, due to the high humidity conditions that develop inside the plastic packing, there have been several rejections from brokers due to the presence of fungal diseases. The aim of this work was to identify morphological (optical microscopy and scanning electron) and molecularly (PCR: Polimerase Chain Reaction) the species of the causal fungi of the main postharvest diseases of chayote fruits for export, as well as in vitro tests of the effectiveness of various commercial products as inhibitors of the growth of these fungi. The results show that Didymella bryoniae is the cause of "gummosis of cucurbits", while Fusarium oxysporum and F. solani cause fusarium head blight or drowning of guides; these pathogens damage the basal and median part of marketable fruit, in addition to Chaetomium globosum as associate of the infectious process
\end{abstract}

\footnotetext{
** Universidad Autónoma Chapingo, km 38.5 Carretera México-Texcoco, Chapingo, Texcoco, Estado de México, C.P. 56230 México.

*** Campus San Luis Potosí, Colegio de Postgraduados. Iturbide 73. Salinas Hidalgo, San Luis Potosí. CP 78621. México.
} 
sp., como saprófito no patógeno. La inoculación con Bacillus subtilis presentó una inhibición efectiva $\left(0,01 \mathrm{mg} . \mathrm{l}^{-1}\right.$ i.a) en las pruebas in vitro contra Didymella bryoniae, Fusarium oxysporum y F. solani; el fungicida más efectivo contra los 2 primeros fue Tebuconazole-trifloxystrobin, con una DL50 de 0,0116 y 0,0106 mg. $\mathrm{l}^{-1}$ respectivamente; no así contra $F$. solani, cuyo mayor control fue registrado con procloraz, con DL50 de $0,0042 \mathrm{mg} \cdot \mathrm{l}^{-1}$. Estos resultados contribuyen al reconocimiento de las enfermedades fungosas más importantes en chayote y su perspectiva de control durante el manejo postcosecha de frutos para exportación.

\section{INTRODUCCIÓN}

La especie Sechium edule (Jacq.) Swartz) (Cucurbitaceae) es originaria de México y Centroamérica, su domesticación data de tiempos precolombinos y fue distribuida por los conquistadores a Europa, Asia, África, Oceanía, Antillas y América del sur. Actualmente su principal explotación comercial se ubica principalmente en México, y Costa Rica, sin embargo, también se produce en Brasil, Cuba, India, Taiwan y China. Dentro de la variación infraespecífica que presenta S. edule, el grupo varietal virens levis (verde liso) es el de mayor demanda, del cual México es el primer productor-exportador mundial seguido de Costa Rica (Cadena et ál. 2013), y representa una importante fuente de empleo local rural y generador de divisas (SIAP 2013). El fruto de chayote es una baya turgente con epidermis delgada que la hace susceptible a daños causados por roce, compresión e impacto que facilita el ataque de hongos durante la poscosecha y transporte, lo cual ocasiona rechazo en los mercados. Una característica importante del fruto es la presencia de estomas funcionales (Cadena et ál. 2007) que al realizar intercambio de gases, crean un ambiente de alta humedad en la envoltura individual, que facilita la germinación de esporas e caused for Fusarium sp., as a non-pathogenic saprophyte. Bacillus subtilis, had an effective inhibition $\left(0,01 \mathrm{mg} . \mathrm{l}^{-1}\right.$ a.i.) in vitro tests against Didymella bryoniae, Fusarium oxysporum and $F$. solani. Tebuconazole-trifloxystrobin was the most effective fungicide against the first 2 , with an LD50 value of 0,0116 and $0,0106 \mathrm{mg} . \mathrm{l}^{-1}$ respectively; not so against $F$. solani, where prochloraz was more effective, with a LD50 value of $0,0042 \mathrm{mg} \cdot \mathrm{l}^{-1}$. These results contribute to the recognition of the most important fungal diseases in chayote and their prospects for control during the postharvest handling of fruits for export.

ingreso de los haustorios durante el tránsito. Aun cuando el transporte se realiza entre $45-50^{\circ} \mathrm{F}$ $\left(7-10^{\circ} \mathrm{C}\right)$ con $85 \%$ de humedad relativa, existen rechazos mayores al $20 \%$, ya que la infección ocurre tanto por daños mecánicos como por quemaduras por frío durante el transporte (Cadena et ál. 2006). Con el fin de identificar los hongos causantes de pudriciones en frutos de chayote de exportación, se realizó el aislamiento, caracterización morfológica, molecular y patogenicidad de los hongos aislados de frutos en postcosecha así como pruebas in vitro para evidenciar la efectividad de diversos fungicidas y Bacillus subtilis comerciales sobre el control del crecimiento de éstos patógenos.

\section{MATERIALES Y MÉTODOS}

\section{Material vegetal}

Se utilizaron frutos de chayote (S. edule) del grupo varietal virens levis cultivar Campiña ${ }^{\mathrm{TM}}$ procedentes de huertas de exportación ubicadas en Amatlán de los Reyes, Veracruz $\left(19^{\circ} 04^{\prime} \mathrm{N}\right.$, $97^{\circ} 03^{\prime} \mathrm{O}$ y altitud de $860 \mathrm{~m}$ ). Los frutos se cosecharon en madurez hortícola a $18 \pm 2$ días después de antesis (Aung et ál. 1996) con síntomas 
visuales de pudrición para realizar el aislamiento y purificación de los hongos.

\section{Aislamiento de hongos}

Se cortaron trozos de 20 frutos que presentaban lesiones con tejido enfermo y sano (aproximadamente $125 \mathrm{~mm}^{3}$ ), se desinfestaron con hipoclorito de sodio al 3\% por 2 minutos, y se lavaron posteriormente con agua destilada estéril por 3 veces. Los trozos se secaron con papel filtro esterilizado y fueron puestos 4 trozos por caja petri en medio de cultivo Papa-DextrosaAgar (PDA) a temperatura ambiente de $23^{\circ} \mathrm{C} \pm 2$ por 5 días. Los hongos que crecieron se aislaron individualmente en cajas petri en medio PDA y medio Agua-Agar (AA), dejándolos crecer a temperatura ambiente por 5 días. De los nuevos crecimientos se hicieron cortes de punta de hifa para obtener aislados puros y homogéneos a partir de los cuales se obtuvieron los cultivos monospóricos, transfiriéndolos a tubos de ensayo con PDA cubiertos de aceite mineral estéril y seguir los postulados de Koch (Agrios 2005).

\section{Identificación molecular}

De cada cepa obtenida, se realizó una siembra en medio Papa-Dextrosa (PD) y fueron incubados por 12 días en agitación constante a 1,5 rpm a temperatura ambiente, y posteriormente se hizo la extracción de ADN por el método AP, una vez verificada su calidad por electroforesis en gel de agarosa al 1\%. Para la amplificación de ADN por Reacción en Cadena de la Polimerasa (PCR), se adicionó en un tubo de micro centrifuga el buffer PCR 1x, $\mathrm{MgCl}_{2} 1,5 \mathrm{mM}$, dNTPs $200 \mu \mathrm{M}$, ITS'4 20 pM, ITS'5 20pM, Taq DNA Pol 1,25 u, muestra de ADN de 50-100 nM y agua de PCR hasta completar $50 \mu \mathrm{L}$. Los iniciadores utilizados fueron universales (ITS'4 e ITS'5), y una vez completada la mezcla se procedió a meter las muestras al termociclador bajo las siguientes condiciones: para desnaturalización inicial un ciclo de $5 \mathrm{~min}$ a $95^{\circ} \mathrm{C}$, para anillamiento 30 ciclos de 1 min a $55^{\circ} \mathrm{C}$, para extensión 30 ciclos de un min a $72^{\circ} \mathrm{C}$, y para extensión final un ciclo de 12 min a $72^{\circ} \mathrm{C}$. Las muestras amplificadas fueron visualizadas en un gel de agarosa $(1,5 \%)$ en TBE por medio de un marcador molecular de 100 pares de bases (pb). La electroforesis se realizó al inicio con 20 Volts por $5 \mathrm{~min}$, y posteriormente a 80 volts por $35 \mathrm{~min}$. Trascurrido el tiempo se observó el gel bajo luz ultravioleta con un fotodocumentador UVP®. El producto PCR se limpió con el kit Wizard® SV Gel and PCR Clean-Up System. Una vez limpio el ADN se corrió nuevamente en gel agarosa al 1,5\%. Las muestras fueron secuenciadas a la Unidad de Biología Molecular del Instituto de Fisiología Celular de la Universidad Nacional Autónoma de México.

\section{Pruebas de patogenicidad}

Por cada cultivo monospórico obtenido se inocularon 5 frutos sanos procedentes de huertas comerciales para exportación, previamente desinfectados con hipoclorito de sodio $(1,5 \%)$ y lavados con agua destilada esterilizada. La inoculación se realizó por aspersión con una concentración de $1 \times 10^{6}$ UFC. Posteriormente, los frutos se colocaron en recipientes dentro de bolsas de plástico y se sellaron con el fin de crear una cámara húmeda que se mantuvo en el laboratorio bajo condiciones naturales de luz y oscuridad y temperatura ambiente $\left( \pm 25^{\circ} \mathrm{C}\right)$. Los recipientes fueron previamente desinfectados con etanol (70\%), toallas de papel esterilizadas y una malla que evitó el contacto directo del fruto con la fuente de humedad. El periodo de incubación fue de 12 días, en el cual se evidenciaron síntomas de pudrición. Los hongos fueron nuevamente aislados en cultivos puros a partir de los frutos inoculados y se compararon con los aislamientos inoculados originalmente.

\section{Caracterización morfológica}

Por cada aislamiento se registró el crecimiento micelial, pigmentación y formación de estructuras reproductivas para identificarlas morfológicamente con base en color, forma de la colonia, crecimiento del micelio y forma de conidios. Mediante las claves de Barnett y 
Hunter (1986) se identificaron todos los hongos aislados. Para observar las estructuras en el microscopio compuesto, se hicieron preparaciones permanentes de las colonias en glicerol al $50 \%$ acidificado con 5 gotas de una solución de ácido clorhídrico $(12 \mathrm{~N})$.

Por otro lado del medio de cultivo de AA se tomaron 4 muestras para aislamientos que se fijaron en una solución de glutaraldehído $(2,5 \%)$ y amortiguador de fosfatos Sorensen's ${ }^{\mathrm{TM}}$ por 24 h. Posteriormente, las muestras fueron enjuagadas 3 veces con el amortiguador de fosfatos por 5 min cada una. El proceso de deshidratación de las muestras, se realizó con etanol con cambios de 45 min en concentraciones graduales desde $30 \%$ hasta $100 \%$; se secaron a punto crítico (Samdri- $780^{\circledR}$ ) y colocadas en porta muestras metálico con cinta doble adhesiva de carbón, recubiertas con oro por 4 min para su ionización. Las muestras fueron observadas y fotografiadas en el microscopio electrónico de barrido modelo Jeol JSM 6390.

\section{Efectividad in vitro de agentes de control}

Se probó la efectividad de 3 fungicidas (Tebuconazole-trifloxystrobin (Consist max ${ }^{\circledR}$ ); Procloraz (Sportak $\left.{ }^{\circledR}\right)$ y Difenoconazol (Score $\left.{ }^{\circledR}\right)$ (EPA 2004, USDA 2015), así como, Bacillus subtilis (SERENADE®) en el crecimiento micelial de Didymella bryoniae, Fusarium oxysporum y $F$. solani. Estos fungicidas están aprobados en México para el control de mildiú
(Psudoperonospora spp.) y cenicilla (Podosphaera sp. y Golovinomyces sp.) en cucurbitáceas, pero no existen reportes de su uso en el control de hongos de chayote; mientras que SERENADE® es un fungicida-bactericida biológico de acción preventiva recomendado para el control o supresión de las enfermedades causadas por hongos de uso permitido. Las cepas evaluadas se encontraban preservadas en aceite mineral estéril. Previo a su utilización, fueron incrementadas en medio de cultivo papa dextrosa agar (PDA). Se preparó una solución madre (stock) de $5000 \mathrm{mg} . \mathrm{l}^{-1}$ de ingrediente activo (i.a.) del cual se derivaron las diluciones. El medio de cultivo se esterilizó en una autoclave por $15 \mathrm{~min}$ a $121^{\circ} \mathrm{C}$, transcurrido el tiempo se dejó enfriar hasta los $40^{\circ} \mathrm{C}$ y se añadieron las cantidades correspondientes de cada solución de los fungicidas, para obtener las concentraciones evaluadas fueron: 0,$01 ; 0,1$; 1,$0 ; 10 ; 100 ; 500 ;$ y 1000 mg. $\mathrm{l}^{-1}$. El fungicida ya mezclado uniformemente en el medio de cultivo estéril se colocó en cajas Petri de $9 \mathrm{~cm}$ de diámetro, sobre las cuales ya solidificadas se colocaron discos con crecimiento micelial de $5 \mathrm{~mm}$ de diámetro. Se incluyó una variante con medio de cultivo sin fungicida como testigo, y cada variante se replicó 10 veces. Las cajas inoculadas se incubaron a $25 \pm 2^{\circ} \mathrm{C}$. El efecto inhibitorio de los fungicidas se determinó como porcentaje de inhibición del crecimiento radial del micelio $(\mathrm{mm})$ en cada hongo en relación con el testigo. Para el cálculo del porcentaje de inhibición de crecimiento se utilizó la fórmula de Abbot (CIBA 1981):

$$
\% \text { de Inhibición }=\frac{\text { Crecimiento colonia testigo }- \text { Crecimiento colonia concentración }}{\text { Crecimiento colonia testigo }} \times 100
$$

Se determinaron los valores DL-50 y DL-95, según el porcentaje de inhibición del crecimiento micelial del hongo a los $8 \pm 2$ días de inoculación. Las DL-50 y DL-95 se calcularon mediante el análisis Probit en el paquete estadístico SAS 9.0 (System for Windows). Se utilizó la prueba de comparación múltiple entre medias por el método de Tukey $(\mathrm{p} \leq 0,05)$.

\section{RESULTADOS Y DISCUSIÓN}

\section{Aislamiento e identificación molecular de hongos asociados}

Se obtuvieron 20 cepas de los frutos que presentaron síntomas de enfermedad en la parte media y basal del fruto; y de acuerdo con los 
postulados de Koch se obtuvieron 11 positivas, después de 2 aislamientos, y 5 tuvieron características similares en su colonia. Cada una de las secuencias obtenidas fueron alineadas en el Centro Nacional de Información sobre Biotecnología (NCBI) con un resultado que dio homología de $100 \%$ para Didymella bryoniae; $100 \%$ para Fusarium oxysporum y F. solani y $99 \%$ para Chaetomiun globosum.

\section{Pruebas de patogenicidad y características morfológicas}

Los síntomas presentados en chayote por $D$. bryoniae, fueron la presencia de colonias oscuras tanto en el área basal y media del fruto, aspecto que provocó pudrición seca. La invasión de este hongo se presentó a los 10 días de incubación en cámara (Figura 1). Sobre las áreas afectadas se observó coloración amarillenta alrededor de la pudrición y en la superficie micelio blanco. El desarrollo de este hongo se promueve en condiciones de alta humedad relativa. $D$. bryoniae presenta picnidios de 80 a $170 \mu \mathrm{m}$ de diámetro. Las picniosporas son de tamaño variable, ya que algunos picnidios las producen muy pequeñas, bi o tricelulares de 13 a $20 \mu \mathrm{m}$ x 4 a $6 \mu \mathrm{m}$. Los peritecios tienen un diámetro que oscila entre los 80 $\mu \mathrm{m}$ y $170 \mu \mathrm{m}$ y las ascas miden entre $44-56$ x 7-11 $\mu \mathrm{m}$. Las ascosporas son ovoides con 2 células desiguales de $9 \mu \mathrm{m}$ a $13 \mu \mathrm{m} \times 4-5 \mu \mathrm{m}$.
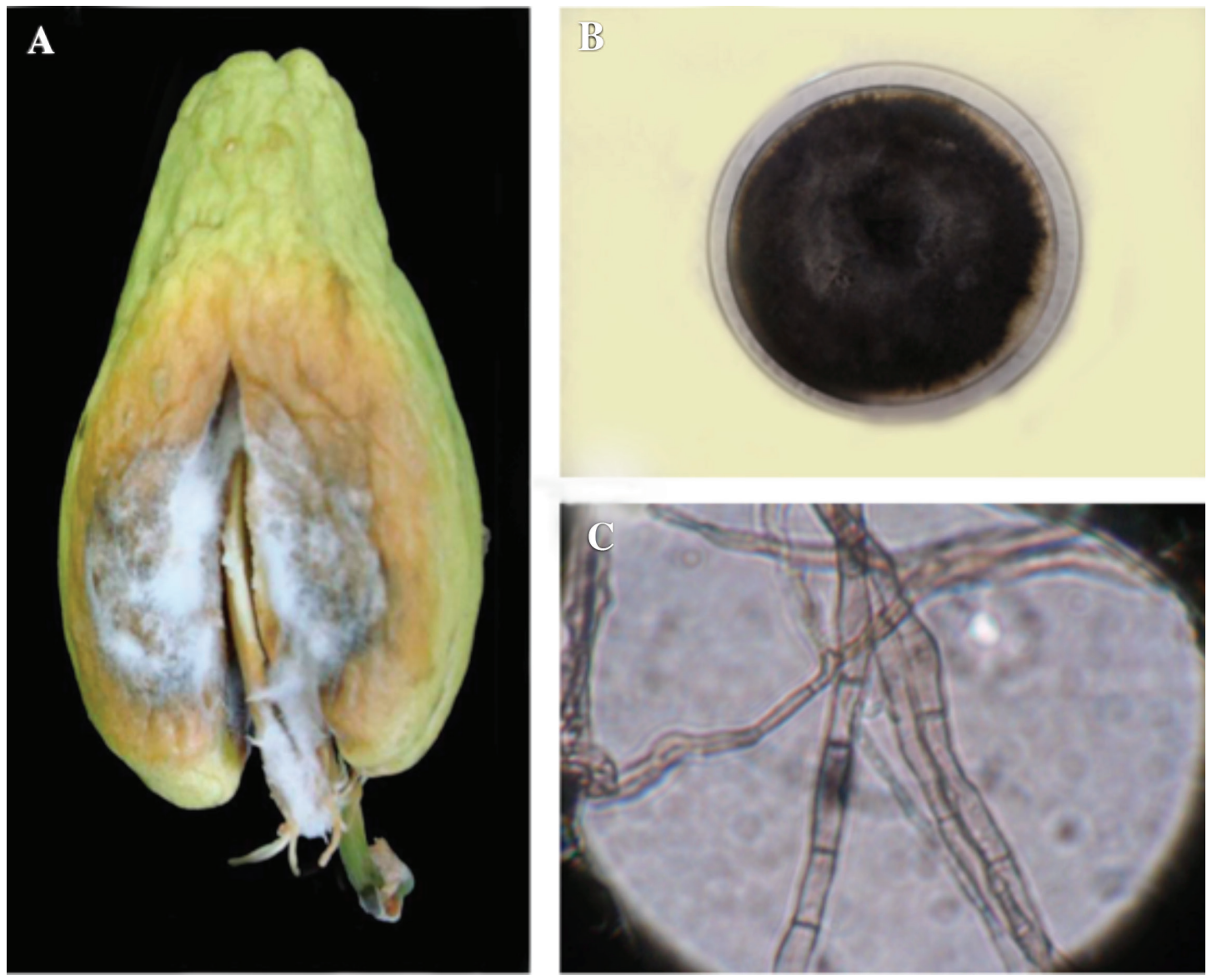

Fig. 1. A) Síntoma en fruto enfermo por Didymella bryoniae. B y C) Didymella bryoniae en medio de cultivo PDA, y micelio $(40 \mathrm{X})$ respectivamente. 
De acuerdo con Messiaen et ál. (1995) $D$. bryoniae puede atacar tallos y frutos, $\mathrm{y}$, en ciertos casos a las hojas. Es característico de los climas tropicales y subtropicales húmedos pudiéndose además, desarrollar durante el verano en países templados cálidos y lluviosos. Puede provocar en los tallos lesiones de color claro, en un principio de margen eventualmente irregular, pero bien delimitado. Sobre estas lesiones el hongo fructifica y produce picnidios (diseminación de picniosporas por la lluvia) y peritecias a la vez (proyección de ascosporas). En los bordes de las lesiones que afectan a los tallos se pueden producir exudaciones de gomas, de donde se deriva el nombre de "cancro gomoso" o "gomosis", primero de aspecto verde aceitoso oscuro con un margen amarillo que se extiende desecándose hacia al centro. En el fruto de chayote provoca manchas angulares sobre las hojas y lesiones sobre los frutos maduros que dan origen a una pudrición seca. El control de D. bryoniae se basa en la eliminación de las plantas enfermas, además de utilizar semillas sanas, a partir de que los frutos de los cuales se extrae, carezcan de lesiones.
Los síntomas que se presentaron en los frutos de chayote atribuidos a Fusarium oxysporum, fueron un micelio blanco en la parte basal y media del fruto, con una pudrición blanda alrededor de coloración amarilla. Los síntomas se presentaron en los frutos a los 4 días de incubación en las cámaras húmedas, y para los 12 días de incubación el fruto se mostró con pudriciones que cubrieron la mitad de la superficie. El hongo en el medio de cultivo PDA el micelio mostró una coloración púrpura al centro y alrededor coloración blanca (Figura 2 B), lo cual coincide con lo que menciona Barnett y Hunter (1986) al describir las características de las colonias de este patógeno. Los macroconidios son falcados con monofialides en forma de botellas, microconidos fusiformes de forma oval-elipsoide, de un tamaño de 6-15 $\mu \mathrm{m} \times 3-3,5 \mu \mathrm{m}$; los macroconidios hialinos, presentaron de 3 a 5 septas transversales alargados con el ápice puntiagudo y la base en forma de pie, de pared delgada, y midieron de 34-60 $\mu \mathrm{m} \times 3-5 \mu \mathrm{m}$. 


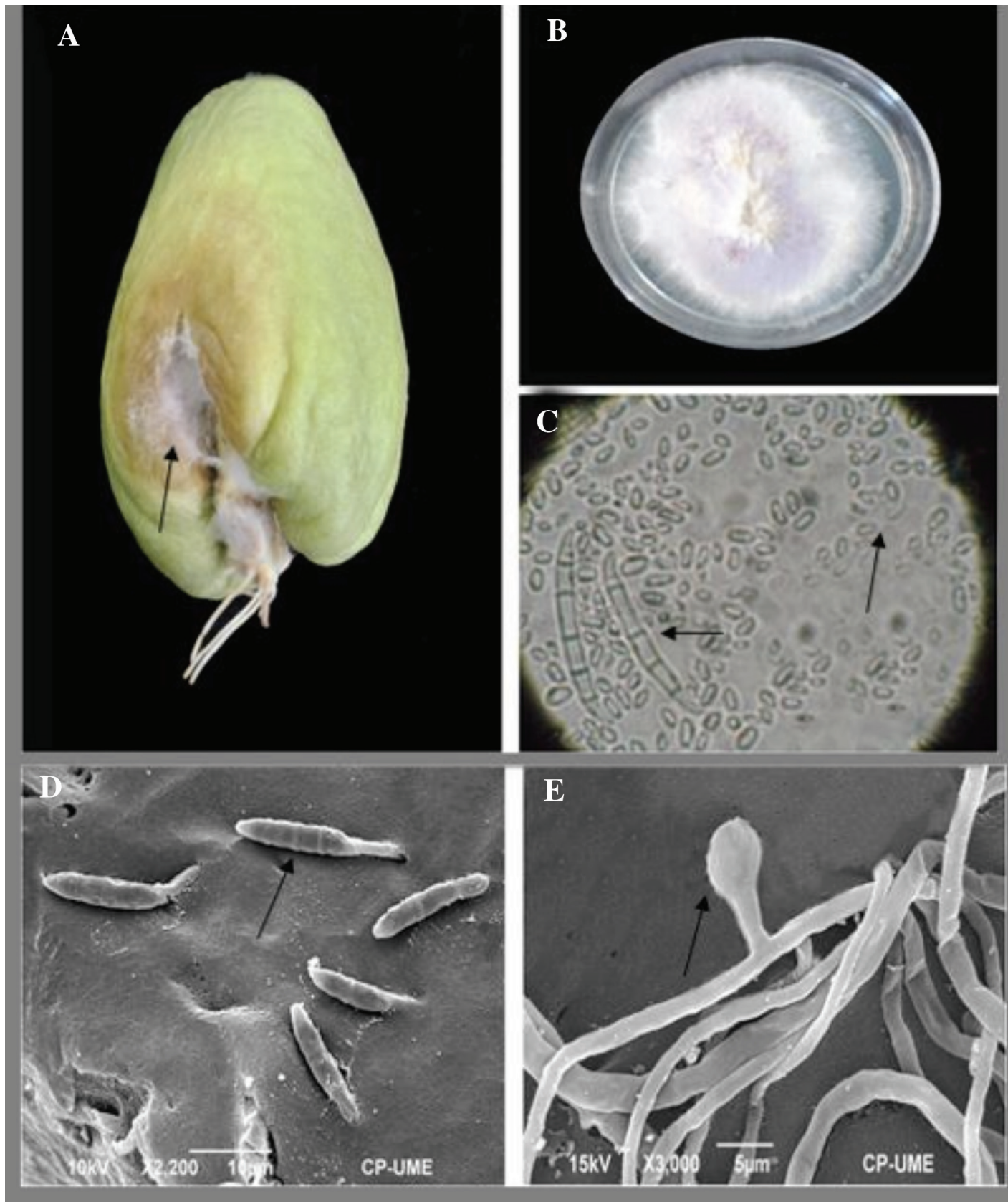

Fig. 2. A) síntomas causados en frutos de chayote por Fusarium oxysporum. B) F. oxysporum en medio de cultivo PDA. C) Macroconidios y microconidios de F. oxysporum (40X). D) Micrografía de microscopio electrónico de barrido (2200X) de macroconidios. E) Micrografía de microscopio electrónico de barrido (3000 X) de una clamidospora de F. oxysporum. 
Los primeros síntomas en los frutos atribuidos a Fusarium solani fueron a los 5 días de incubación en cámara húmeda que mostraron un micelio de color blanco en la epidermis de la parte media del fruto; a los 12 días se manifestó podredumbre tanto en la parte basal, como en la parte media del chayote, con el micelio blanco. La pudrición fue blanda, con una coloración amarilla (Figura 3 A). El crecimiento de la colonia en medio de cultivo PDA fue con una coloración del micelio amarillo con un centro en color verde-azul, y otra colonia de color amarillo en su totalidad (Figura 3 B y 3 C).
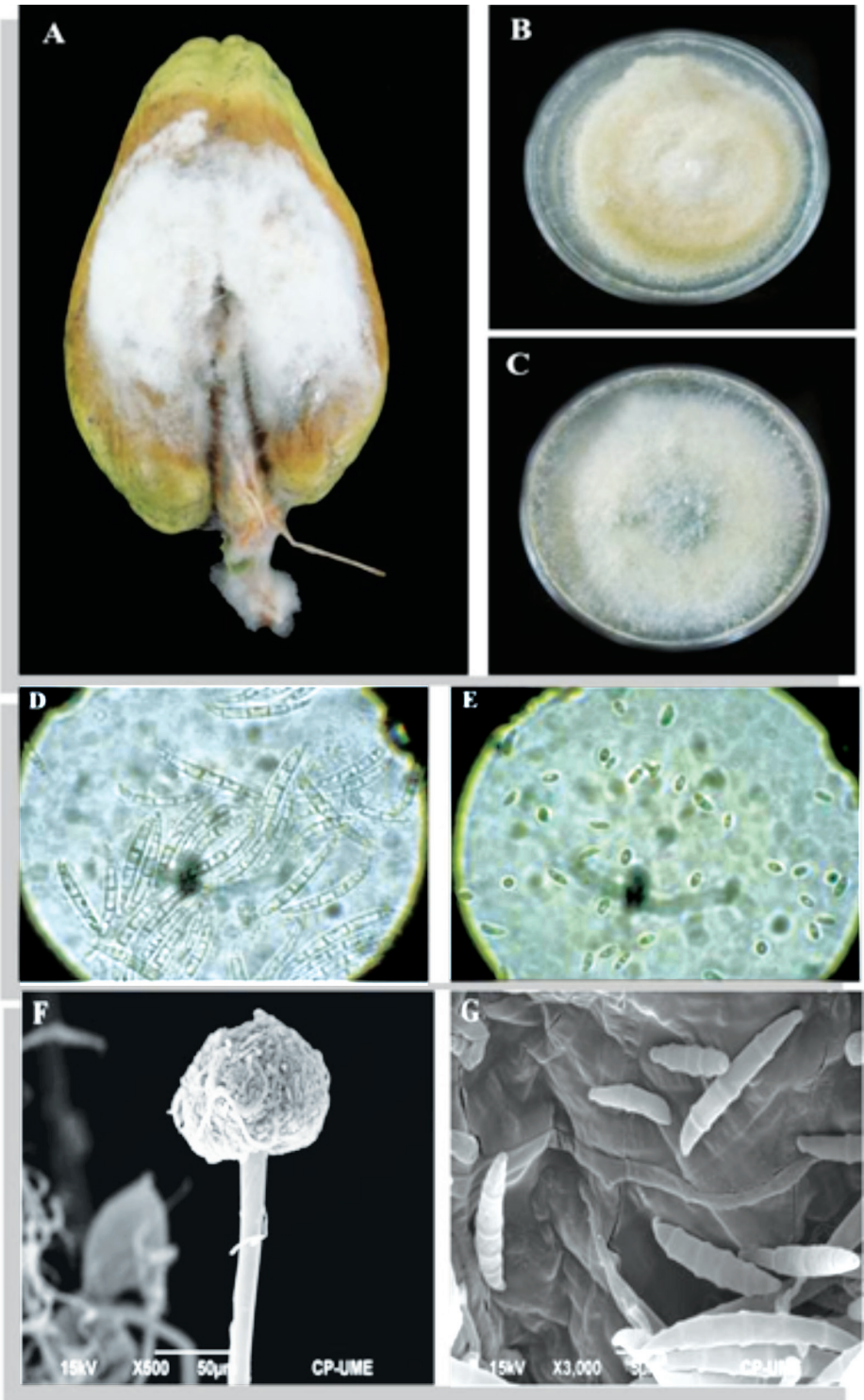

Fig. 3. A). Síntomas causados en frutos de Sechium edule por Fusarium solani. B y C). F. solani en medio de cultivo PDA. D y E). Macroconidios y microconidios de F. solani (40X). F). Micrografía de microscopio electrónico de barrido (500X) de un conidióforo de F. solani G). Micrografía de microscopio electrónico de barrido (3000 X) de macroconidios. 
Fusarium solani presenta microconidias, con 3 tabiques que miden de $20 \mu \mathrm{m}$ a $50 \times 3,5$ a $6,0 \mu \mathrm{m}$ y con 5 tabiques de $26 \mu \mathrm{m}$ a $70 \mathrm{X} 4$ a 6 $\mu \mathrm{m}$. Puesto que Fusarium sp., es un hongo que se encuentra en el suelo, es común que los frutos que se hallan en contacto con este, pueden ser afectados en primer lugar por lesiones circulares pardas que alcanzan de 1 a $2 \mathrm{~cm}$ de diámetro y que pueden ser confluyentes. El micelio puede alcanzar en interior del fruto y contaminar la semilla, para compensar de este modo, su débil persistencia en el suelo. De acuerdo con estos resultados, es importante destacar que los rechazos de fruto se presentan en frontera por la presencia de hongos, pues estos requieren de por lo menos 6 días para desarrollarse. Dussel (2008) menciona que generalmente el tiempo que transcurre desde el embarque hasta los puntos de distribución de los productos mexicanos a Estados Unidos puede tomar más de 2 semanas, a pesar de la cercanía, tiempo suficiente para la esporulación y diseminación en los frutos.

Los síntomas presentes en frutos de chayote por Chaetomium globosum fueron similares a los de Fusarium sp., debido a que C. globosum no es un hongo fitopatógenos sino saprófito, su alimentación consiste en material rico en celulosa, indirectamente son importantes en la agricultura porque entre los productos que excretan se han descubierto sustancias antagónicas a Fusarium sp. (Sibounnavong et ál. 2012). C. globosum es un Ascomycete que fructifica y forma ascomas diminutos gregarios, piriformes a globulosos, peritecioides (provistos de un ostiolo apical y con los ascos que tapizaron el interior del ascoma), cubiertos por largos y densos pelos rizados, de color amarillo-verdoso. Las esporas son limoniformes, biapiculadas de 10-12 $\mu \mathrm{m} \times 8-9 \mu \mathrm{m}$. La colonia en medio de cultivo PDA mostró una coloración verde (Figura 4). 

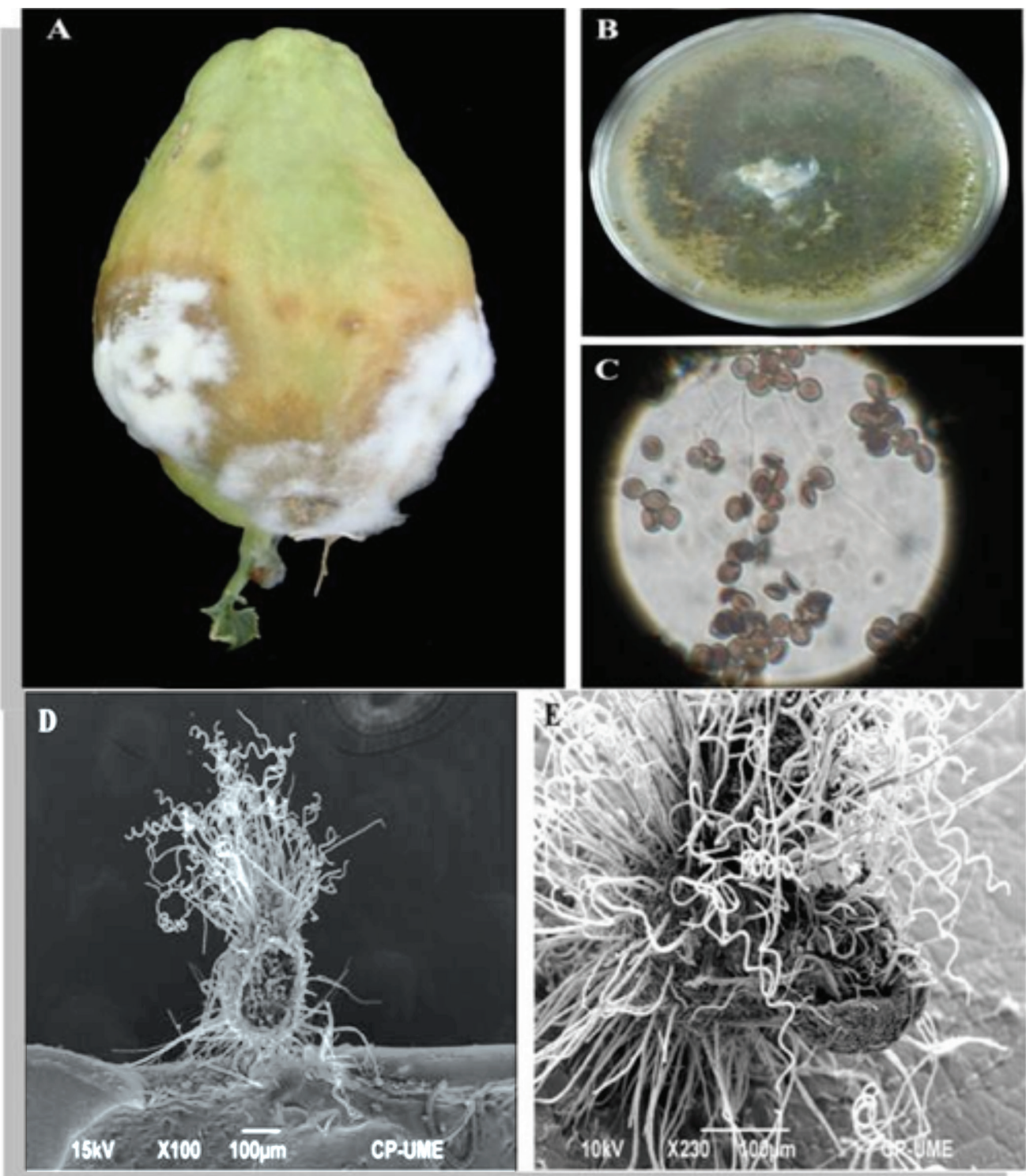

Fig. 4. A) Síntomas causados en frutos de Sechium edule por Chaetomium globosum. B) C. globosum en medio de cultivo PDA. C) Conidios de C. globosum (40X). D y E) Micrografía de microscopio electrónico de barrido (100X) y ascomas de C. globosum (230X).

\section{Efectividad in vitro de agentes de control}

Bacillus subtilis es un agente de control biológico ampliamente utilizado por su efectividad sobre un amplio número de patógenos postcosecha, tales como, Alternaria alternata, Botrytis spp., Colletotrichum sp., Monilinia fructicola y Penicillium expansum, entre otros. En el caso de D. bryoniae, Fusarium oxysporum y F. solani se observó una inhibición superior al 50\% a una concentración de 0,01 mg.l-1 (Figuras 5 a 7). Swain 


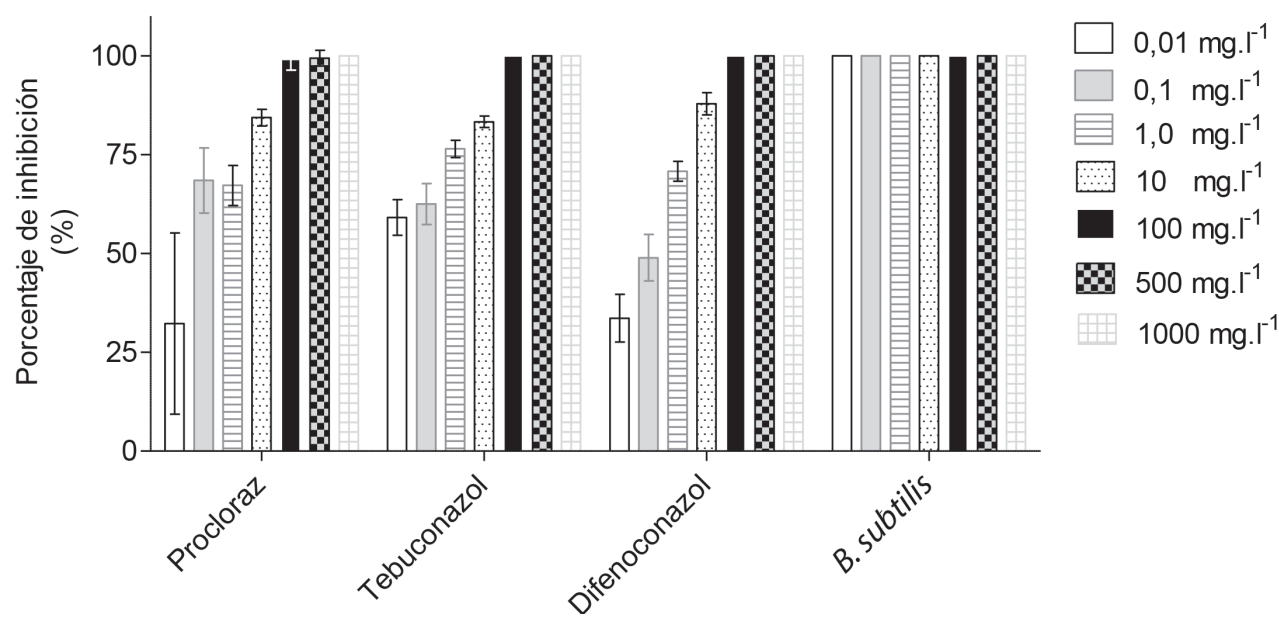

Fig. 5. Porcentaje de inhibición en el crecimiento micelial de Didymella bryoniae con diferentes fungicidas y Bacillus subtilis. ( $\mathrm{n}=10 \pm$ desviación estándar).

Las barras de izquierda a derecha indican concentraciones de 0,$01 ; 0,1 ; 1,0 ; 10 ; 100 ; 500$ y 1000 mg. $1^{-1}$ de cada ingrediente.

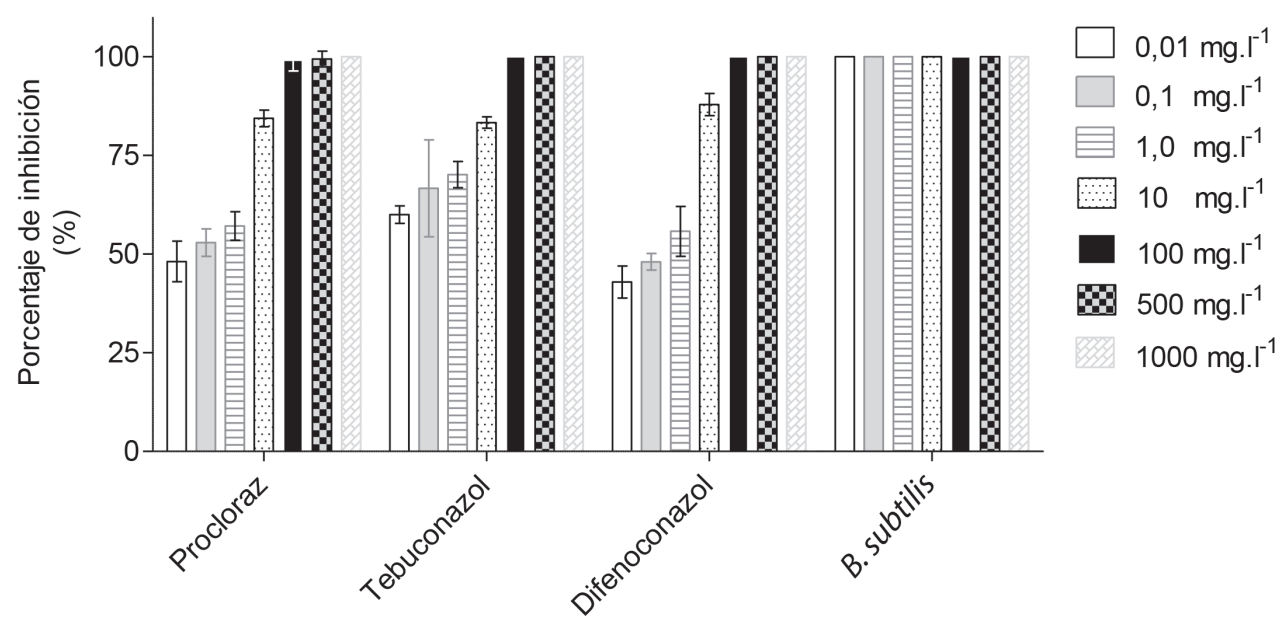

Fig. 6. Porcentaje de inhibición en el crecimiento micelial de Fusarium oxysporum tratado con fungicidas y Bacillus subtilis ( $\mathrm{n}=10 \pm$ desviación estándar).

Las barras de izquierda a derecha indican concentraciones de 0,$01 ; 0,1 ; 1,0 ; 10 ; 100 ; 500$ y 1000 mg. $1^{-1}$ de cada ingrediente. 


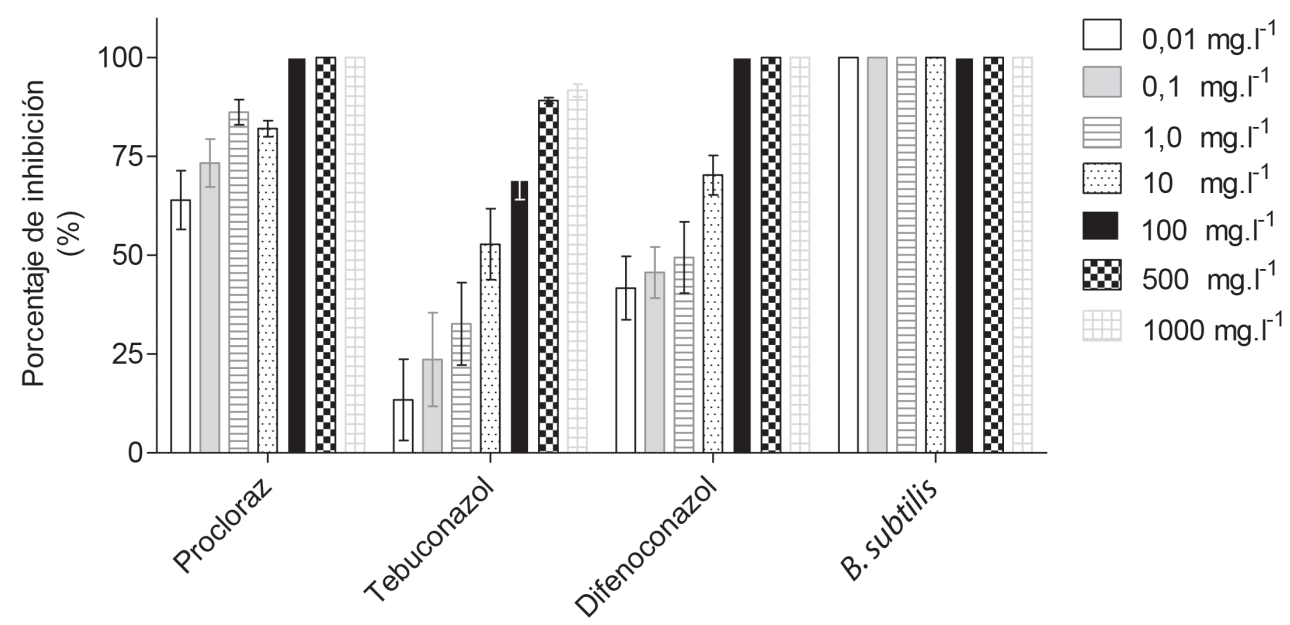

Fig. 7. Porcentaje de inhibición en el crecimiento micelial de Fusarium solani tratado con fungicidas y Bacillus subtilis ( $\mathrm{n}=10 \pm$ desviación estándar).

Las barras de izquierda a derecha indican concentraciones de 0,$01 ; 0,1 ; 1,0 ; 10 ; 100 ; 500$ y 1000 mg.1 $1^{-1}$ de cada ingrediente.

et ál. (2008) probaron la efectividad de B. subtilis contra Fusarium oxysporum como hongo patógeno postcosecha sobre ñame (Dioscorea rotundata L.) que registró la inhibición del crecimiento del hongo en condiciones in vitro en medio líquido de 49,3-56,6\% y en medio sólido al quinto día de incubación de hasta $31 \%$. El efecto inhibitorio de $B$. subtilis se basa en la producción de enzimas extracelulares que afectan la pared celular de los hongos fitopatógenos, además de producir diferentes polipéptidos de actividad antibiótica, tales como, bacilomicina, iturina, bacidisina, fengimicina y micobacilina (Soda 2000, Utkhede y Sholberg 1986).

El fungicida que registró mejor control sobre el crecimiento de D. bryoniae y Fusarium oxysporum in vitro para una DL50 se logró con el tebuconazole-trifloxystrobin con 0,0116 y 0,0106 mg..$^{-1}$ respectivamente. Éste fungicida sistémico pertenece al grupo de los triazoles que afectan la biosíntesis del ergosterol, que actuó sobre la membrana celular, lo cual afecta el crecimiento del tubo germinativo, haustorios y otros órganos de fijación de los hongos. Este producto de origen sintético se ha utilizado con gran éxito en el control de Rhizopus stolonifer en frutos de hueso (Foster et ál. 2007) (Figuras 5 a 7).

Respecto a $F$. solani tuvo una respuesta diferente a $F$. oxysporum, ya que el fungicida que resultó más efectivo en inhibir su crecimiento micelial fue Procloraz (Figura 7) con una DL50 de 0,0042 mg..$^{-1}$ (Cuadro 1). Al evaluar el control in vitro de $F$. solani en la campanilla (Thevetia peruviana) se observó que concentraciones de $450 \mathrm{mg}^{-1} \mathrm{l}^{-1}$ de Procloraz inhibieron el $100 \%$ de crecimiento micelial (Herrera et ál. 2011). Este fungicida al igual que el tebuconazol y difenoconazol, es inhibidor de la biosíntesis de ergosterol, pero se ha utilizado en el manejo postcosecha de frutos con gran éxito pues resulta efectivo contra ciertos hongos que han desarrollado resistencia a los benzimidazoles (Johanson y Blazquez 1992). 
Cuadro 1. Valores de la DL50 y DL95 (mg. $\left.1^{-1}\right)$ de los fungicidas y Bacillus subtilis para el control del crecimiento micelial de Didymella bryoniae, Fusarium oxysporum y Fusarium solani aislados de frutos de Sechium edule.

\begin{tabular}{cccc}
\hline Patógeno & Fungicida & CL50 & CL95 \\
\hline \multirow{2}{*}{ Didymella bryoniae } & Procloraz & $0,0688 \mathrm{a}^{\mathrm{z}}$ & $92,53 \mathrm{a}$ \\
& Tebuconazole-trifloxystrobin & $0,0116 \mathrm{~b}$ & $67,07 \mathrm{~b}$ \\
& Difenoconazol & $0,0848 \mathrm{a}$ & $38,83 \mathrm{c}$ \\
& B. subtilis & $0,01 \mathrm{c}$ & $0,01 \mathrm{~d}$ \\
\hline \multirow{2}{*}{ Fusarium oxysporum } & Procloraz & $0,06087 \mathrm{~b}$ & $481,2 \mathrm{~b}$ \\
& Tebuconazole-trifloxystrobin & $0,0106 \mathrm{c}$ & $170,8 \mathrm{~b}$ \\
& Difenoconazol & $0,1209 \mathrm{a}$ & $1445,3 \mathrm{a}$ \\
& B. subtilis & $0,01 \mathrm{c}$ & $0,01 \mathrm{~b}$ \\
\hline \multirow{2}{*}{ Fusarium solani } & Procloraz & $0,0042 \mathrm{~b}$ & $35,0 \mathrm{~b}$ \\
& Tebuconazole-trifloxystrobin & $4,74 \mathrm{a}$ & $18591,0 \mathrm{a}$ \\
& Difenoconazol & $0,15 \mathrm{~b}$ & $497,0 \mathrm{~b}$ \\
& B. subtilis & $0,01 \mathrm{~b}$ & $0,01 \mathrm{c}$ \\
\hline
\end{tabular}

Valores con la misma letra en la misma columna dentro de cada patógeno son estadísticamente iguales $(\mathrm{p} \leq 0,05)$.

z Los valores de las CL50 y CL95 se calcularon a partir de los porcentajes de inhibición de la germinación conidial y del crecimiento micelial de los medios con fungicida comparado con la ausencia de fungicida, para ello, los porcentajes se transformaron a unidades probit, $\mathrm{y}$ las concentraciones, a logaritmos.

\section{CONCLUSIONES}

Los hongos identificados en frutos de chayote como Didymella bryoniae, Fusarium oxysporum, Fusarium solani y Chaetomium globosum. Estos reprodujeron los síntomas de pudrición en la epidermis y mesocarpo, y se relacionaron con los daños observados durante el almacenamiento y tránsito de frutos. Es probable que Fusarium oxisporum y F. solani sean transportados desde el campo al sitio de empaque, ya que su desarrollo ocurre principalmente en el suelo y pueden ser inoculados indirectamente por actividades de cosecha. La inoculación con Bacillus subtilis mostró efectividad como control biológico contra Didymella bryoniae y Fusarium oxysporum, mientras que el fungicida tebuconazole-trifloxystrobin registró control sobre el crecimiento de $F$. solani, sin embargo, el procloraz fue más efectivo.

\section{LITERATURA CITADA}

AGRIOS G.N. 2005. Plant Pathology, 3rd. ed. Academic Press, Inc.: New York. 803 p.

AUNG L.H., HARRIS C.M., RIJ R.E., BROWN J.W. 1996. Postharvest storage temperature and film wrap effects on quality of chayote, Sechium edule SW. Journal of Horticultural Science 71:297-304.

BARNETT H.I., HUNTER B.B. 1986. Ilustrated genera of imperfect fungi. Fourth Edition. The American Phytopathologycal Society. St. Paul, Minnesota. $218 \mathrm{p}$.

CADENA J., ARÉVALO L., AVENDAÑO C.H., SOTO M., RUIZ L.M., SANTIAGO E., ACOSTA M., CISNEROS V.M., AGUIRRE J.F. OCHOA D. 2007. Production, Genetics, Postharvest Management and Pharmacological Characteristics of Sechium edule (Jacq.) Sw. Fresh Produce, Global Science Books 1:41-52.

CADENA J., ARÉVALO L., RUIZ L., AGUIRRE J., SOTO M., LUNA M., ZAVALETA H. 2006. Quality evaluation and influence of 1-MCP on Sechium edule 
(Jacq.) Sw fruit during -postharvest. Postharvest Biology and Technology 40(2):170-176.

CADENA J., AVENDAÑO C.H., CISNEROS V.M., ARÉVALO M.L., AGUIRRE J.F. 2013. Modelo de Mejoramiento genético participativo en chayote (Sechium sp.). Biblioteca del Colegio de Postgraduados. $69 \mathrm{p}$.

CIBA-GEIGY. 1981. Manual para ensayos de campo en protección vegetal. 2 nd. Edition, Ciba-Geigy S.A. (Biblioteca Cátedra). Basilea, Suiza. 205 p.

DUSSEL E.P. 2008. Los costos de transporte en las exportaciones mexicanas. Vicepresidencia de Sectores y Conocimiento Sector de Integración y Comercio. 49 p. Disponible en http://idbdocs.iadb. org/wsdocs/getdocument.aspx?docnum $=1802667$

EPA. 2004. United States Office of Prevention, Pesticides Environmental Protection and Toxic SubstancesAgency (7505C) Pesticide Fact Sheet. Office of Pesticide ProgramsRegistration Division (7505C) US EPA Ariel Rios Building 1200 Pennsylvania Ave.Washington, DC 20460. 17 p.

FOSTER H., DRIEVER G.F., THOMPSON D.C., ADASKAVEG J.E. 2007. Postharvest decay management for stone fruit crops in California using the "reduced-risk" fungicides fludioxonil and fenhexamid. Plant Disease 91:209-215.

HERRERA E., BACAB I.M., ALEJO J.C., TUN J.M., RUIZ E. 2011. Patogenicidad de Fusarium solani (Mart.) Sacc. y Alternaria alternata (Fries) Keissler en Thevetia peruviana (Pers.) K. Schum., y su control in vitro. Fitosanidad 15(4):231-236.

JOHANSON A., BLAZQUEZ B. 1992. Fungi associated with banana crown rot on fieldpacked fruit from the
Windward Islands and assessment of their sensitivity to the fungicides thiabendazole, prochloraz and imazalil. Crop Protection 11:79-83.

MESSIAEN C.M., BLANCARD D., ROUXEL F., LAFON R. 1995. Enfermedades de las hortalizas. $3^{a}$ Edición. Mundi-Prensa. Madrid: España. 576 p.

SIAP. 2013. Servicio de Información Agroalimentaria y Pesquera. Consultado 2 mayo de 2013. Disponible en http://www.siap.gob.mx/index.php?option=com_wra pper $\&$ view $=$ wrapper $\&$ Itemid $=350$

SIBOUNNAVONG P., SIBOUNNAVONG P., KANOKMEDHAKUL S., SOYTONG K. 2012. Antifungal activities of Chaetomium brasilense $\mathrm{CB} 01$ and Chaetomium cupreum $\mathrm{CC} 03$ against Fusarium oxysporum f.sp., lycopersici race 2. 2012. Journal of Agricultural Technology 8(3):1029-1038.

SODA M. 2000. Bacterial control of plant diseases. J. Biosci. Bioeng. 89:515-521.

SWAIN M.R., RAY R.C., NAUTIYAL C.S. 2008. Biocontrol efficacy of Bacillus subtilis strains isolated from cow dung against postharvest yam (Dioscorea rotundata L.) pathogens. Curr. Mircrobiol 57(5):407-411.

USDA. 2015. United States Department of AgricultureForeign Agricultural Service. Maximum Residue Limits (MRL) Database. Consultado 27 mayo 2015. Disponible en http://www.fas.usda.gov/maximumresidue-limits-mrl-database

UTKHEDE R. S., SHOLBERG P. L. 1986. In vitro inhibition of plant pathogens by Bacillus subtilis and Enterobacter aerogenes and in vivo control of two postharvest cherry diseases. Canadian Journal of Microbiology 32(12):963-967. 